\title{
A comprehensive review on production, surface modification and characterization of nanocellulose derived from biomass and its commercial applications
}

\author{
R. Kumar ${ }^{1}$, B. Rai ${ }^{2}$, S. Gahlyan ${ }^{3}$, G. Kumar ${ }^{1 *}$ \\ ${ }^{1}$ University School of Basic and Applied Sciences, Guru Gobind Singh Indraprastha University, 110078 New Delhi, India \\ ${ }^{2}$ Material Science Division, Shriram Institute for Industrial Research,19 University Road, 110007 Delhi, India \\ ${ }^{3}$ Department of Chemistry, Deenbandhu Chhotu Ram University of Science and Technology, 131039 Murthal, India
}

Received 6 May 2020; accepted in revised form 26 June 2020

\begin{abstract}
The demand for exploring eco-friendly and advanced materials for sustainable development with exceptional physicochemical properties is increasing day by day. Recently, nanocellulose in its all form such as cellulose nanocrystal, cellulose nanofibers, and bacterial cellulose gain great attention in both research and industrial areas due to their appealing inherent properties such as excellent mechanical properties, high concentration of hydroxyl groups for modification, high surface area, lightweight, and biodegradability. However, the hydrophilic nature of nanocellulose restricted its utilization in various applications, but the presence of a functional group on its surface provides a platform for surface modification through various techniques. In this review, the source of nanocellulose, a brief description of the chemical structure of nanocellulose, its type, typical production methods, surface modification, and general application such as textile, biomedical fields, wastewater purification, food packaging are summarized. It is expected to provide broad knowledge about the usefulness of present and future perspectives of nanocellulose for the benefit of the environment and society.
\end{abstract}

Keywords: nanomaterials, cellulose, nanocellulose, eco-friendly, biodegradable polymers

\section{Introduction}

The excessive consumption of non-renewable and non-biodegradable materials such as metals, plastic, glass, etc. has raised serious environmental concerns. As the use of these materials, a large amount of waste generated every year, which remains in the environment for a very long time and produces toxic chemicals or gaseous that affect the health of the living beings. So, extensive research has been conducted to find the alternative of these kinds of materials to reduce the impact of it on the environment [1-3]. In present day's nanotechnology emerge as an outstanding technology in term of its simplicity, cost efficiency, and in a wide variety of applications $[4,5]$. Nanomaterials comprise silica, zirconium, iron oxide, carbonate, and titanium oxide, etc. show outstanding physicochemical properties. Hence these are being used as additives or nanofillers for the development of nanocomposites for various applications. But with many advantages, it has some alarming disadvantages like their health-hazardous effect on human health, which consequent hurdle of its application in biomedical products $[6,7]$. Many research group shows considerable interest in eco-friendly materials that should be biodegradable, renewable, and less toxic [7-9]. Cellulose has been recognized as the most abundant and biodegradable biomaterial having tremendous potential with high productivity. Cellulose is a straight-chain polysaccharide consisting of 1000-15000 $\beta$ glucose units $[10,11]$. It has some

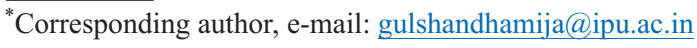

(C) BME-PT 
relevant properties such as low density, combustibility, non-toxicity, and biodegradability that has been utilized for the development of eco-friendly products. Various research groups focused on the development of high-performance polymer composite using cellulosic material as a reinforcement for high throughput applications [12-14]. In this regard, nanocellulose is a great choice of interest because of its biodegradable, biocompatible, renewable, cost-effective, and easy availability, as well as many other inherent features that lead to the enhancement of the performance of the materials $[15,16]$. Various natural resources such as hardwood, softwood, lignocellulosic wastes, grasses, bast fibers, marine animals such as fungi, algae, tunicate, invertebrates are available to produce nanocellulose [17-19]. Natural fiber consists of two distinguished crystalline and amorphous regions, and by the application of chemical and mechanical treatment cellulose nanocrystals and cellulose nanofibers can be produced by the isolation of the crystalline region [20-22]. Cellulose nanocrystals are highly crystalline as compared to cellulose nanofibers having a width of 10-20 nm and length of several micrometers with needle-like structure. On the other hand, cellulose nanofibers have a long fibrous structure having a width similar to or greater than the cellulose nanocrystals composed of alternating crystalline and amorphous domain [23-25]. The utilization of cellulose nanofibers and cellulose nanocrystals has a wide potential in the industrial sector, such as paper, packaging products, plastics, construction materials, automobile parts, and wastewater treatments [26-28]. The presence of abundant primary and secondary hydroxyl groups on the surface of cellulose nanofibers and cellulose nanocrystals, allowing hydrogen bonding with other biopolymers and also helps in surface modification [29, 30]. However, with several advantages of nanocellulose, it possesses some drawbacks like high moisture absorption and poor compatibility with hydrophobic polymers. To overcome these drawbacks, it is required to introduce some covalent or non-covalent interaction between nanocellulose and polymer to produce high-performance composite materials $[16,31]$. The utilization of nanocellulose as a reinforcing agent or filler instead of conventionally used nanomaterials to produce highly efficient composite material for novel applications gain great attention among nanotechnology researchers [20]. Apart from this, in recent years, researchers are being focused on finding out more potential applications of nanocellulose in advanced technological sectors such as energy devices, printing electronics, and three dimensional (3D) printing to open up new markets for nanocellulose [32, 33]. In this review paper, a systematic review of the works has been carried out on the isolation of nanocellulose using different methods from various sources, as well as numerous surface modifications approach to modify nanocellulose for better interaction of nanocellulose with other materials for the development of high-performance composite materials in various fields. Here we also discuss future perspectives and potential applications of nanocellulose.

\section{Source and classification of lignocellulosic fibers}

Natural fibers are renewable, biodegradable, and biocompatible bio-based material found in nature. Complete classifications of natural fiber-based origin, either coming from plants, animals, or mineral fibers, are shown in Figure 1. To extract nanocellulose, varieties of natural fiber are available in nature. Natural fiber has more potential than any other kind of reinforcement or fillers to increase stiffness, tensile

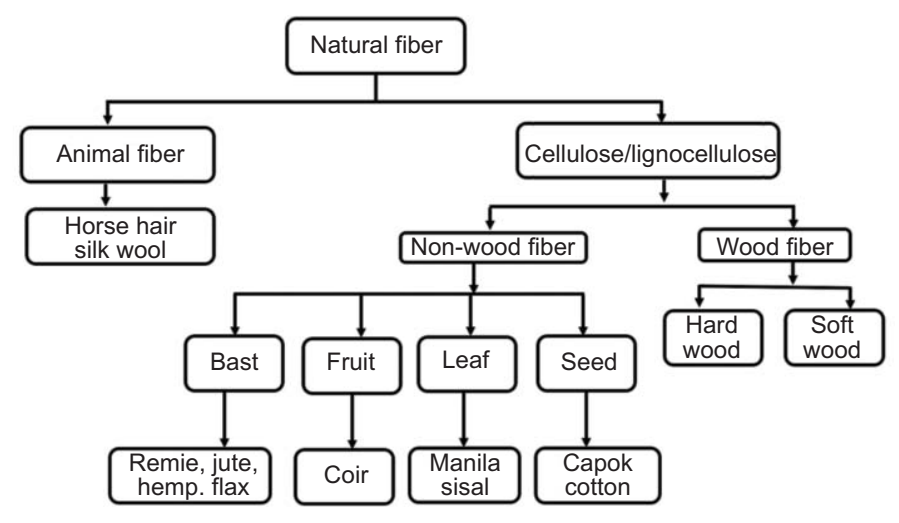

Figure 1. Classification of natural fiber [37, 38]. 
strength, and thermal stability of polymer composite [34-36].

\section{Chemical composition of natural fiber}

Natural fiber mainly consists of hemicellulose, cellulose, and lignin content (Figure 2). Chemical composition and cell structure of the natural fiber are quite complicated. Cellulose is embedded in the matrix of hemicellulose and lignin. Cellulose is the crystalline part of natural fiber, and hemicellulose and lignin are amorphous parts of natural fiber [39-42]. Cellulose is a crystalline content present at about 35 $50 \mathrm{wt} \%$ of the dry weight of biomass, and hemicellulose and lignin are amorphous regions present about $20-35$ and $10-20 \%$ of the dry weight of biomass, respectively $[43,44]$. The percent composition of natural fiber is briefly described in Table 1. Nanocellulose obtained from the cellulosic fiber in the form of fiber and crystal having a diameter less than $100 \mathrm{~nm}$ has gained great attention. This happens due to the high surface area to volume ratio, lighter in weight, high strength, and stiffness as compared to cellulose. Hence, it can be utilized as the superb reinforcing

Table 1. Chemical composition of natural fiber [22].

\begin{tabular}{|l|c|c|c|c|}
\hline $\begin{array}{c}\text { Natural } \\
\text { fiber }\end{array}$ & $\begin{array}{c}\text { Cellulose } \\
{[\mathbf{w t} \%]}\end{array}$ & $\begin{array}{c}\text { Hemicellulose } \\
{[\mathbf{w t} \%]}\end{array}$ & $\begin{array}{c}\text { Lignin } \\
{[\mathbf{w t} \%]}\end{array}$ & $\begin{array}{c}\text { Pectin } \\
{[\mathbf{w t} \%]}\end{array}$ \\
\hline Flax & $60-81$ & $14-18.6$ & 2.3 & $1.8-2.3$ \\
\hline Jute & $51-72$ & $12-20.4$ & $5-13$ & 0.2 \\
\hline Sisal & $43-48$ & $10-13$ & $4-13$ & $0.8-2$ \\
\hline Kenaf & 36 & 28 & 18 & 2 \\
\hline Ramie & $68.6-76$ & $13.1-15.0$ & $0.6-1$ & $1.9-2$ \\
\hline Hemp & $70-78$ & $17.9-22$ & $3.7-5$ & 0.9 \\
\hline Coir & 43 & 0.3 & 45 & 4.0 \\
\hline Banana & $60-65$ & $6-19$ & $5-10$ & $3-5$ \\
\hline Bagasse & 40 & 30 & 20 & 10 \\
\hline Pineapple & $80-81$ & $16-19$ & 12 & $2-2.5$ \\
\hline Wood & $45-50$ & 23 & 27 & - \\
\hline Abaca & $60.8-64$ & 21 & 12 & 0.8 \\
\hline Cotton & $82.7-92$ & $2-5.7$ & $0.5-1$ & 5.7 \\
\hline
\end{tabular}

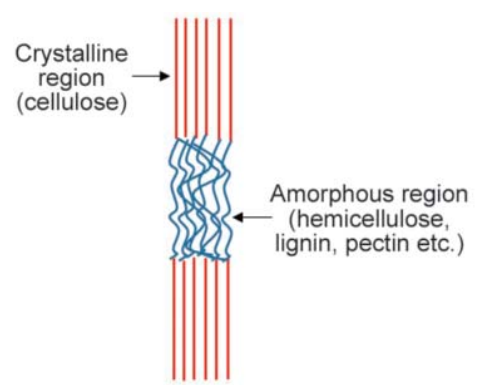

Figure 2. Representation of crystalline and amorphous region of cellulose. agent for developing green nanocomposites for various industrial applications [16, 33, 45].

\section{Nanocellulose}

Cellulose in the form of cellulose fibrils and cellulose crystallites in the nanoscale range can be received by various chemical and mechanical treatments of natural fibers. Nanocellulose is widely categorized into cellulose nanofibers, cellulose nanocrystals, bacterial nanocellulose for the specific applications [22, 46].

\subsection{Cellulose nanofibers}

Cellulose fibrils with nanoscale dimensions are primarily obtained from wood by mechanical and chemical treatment of wood pulp. Cellulose nanofibers comprise both crystalline and amorphous regions [23, 47]. The dimensions of cellulose nanofibers are varied in literature, its width is in the range of 4-20 nm, and the aspect ratio is $L / D(>100 \mathrm{~nm})$. Both individual and aggregate nanofibrils are equally noticed in the CNFs $[48,49]$. Several processes have been employed to obtain cellulose nanofibers from the late 1980s, like the use of high shear mechanical homogenization. However, this process associated with the problem of high energy consumption so, various other techniques have been developed to extract cellulose nanofibers with a reduction in energy consumption up to $98 \%[50,51]$. To lower the cost and energy, numerous techniques of pretreatment such as alkaline, radiation, enzymatic, chemical are typically applied before the mechanical grinding required to separate the staked fibrils. Tempo (2,2,6,6,-tetramethylpiperidin-1-yl) oxidation technique has been frequently used pretreatment before applying the mechanical grinding by homogenization and microfluidization to prepare cellulose nanofibers (Figure 3). The resulting cellulose nanofibers appear as gel-like and once developed into a film, display high tensile strength, low thermal expansion, high mechanical integrity, as well as limited oxygen transmission rate $[52,53]$. Thus these unique properties permit the utilization of cellulose nanofibers film in an electronic device, pharmaceutical, food packaging, and printing applications [54]. However, it has some limitations, which hinder their use in many applications like polymer composite due to the poor compatibility of CNFs with hydrophobic polymer and in the papermaking due to slow dewatering. So various chemical modification was employed on cellulose nanofibers to reduce the concentration of hydrophilic hydroxyl group $[55,56]$. 


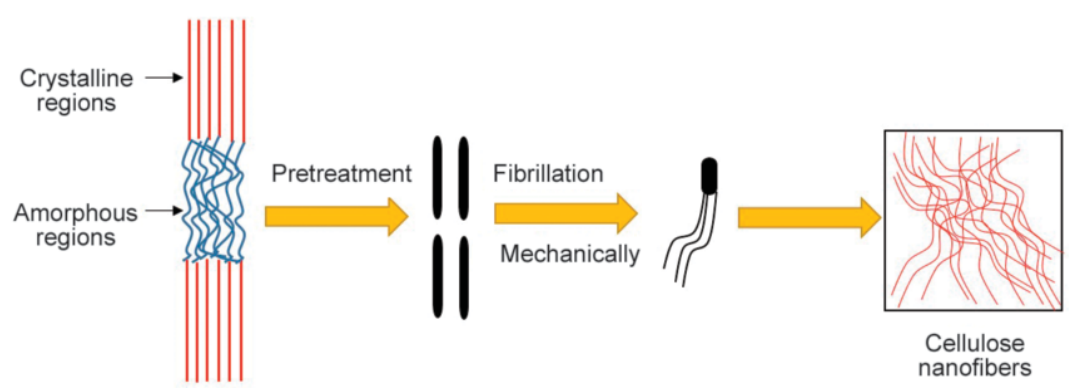

Figure 3. Schematic illustration for the extraction of cellulose nanofibers.

\subsection{Cellulose nanocrystals}

The term cellulose nanocrystals describe whisker shaped CNCs configuration. Cellulose nanocrystals are produced from various natural sources such as cotton, manila, tunicin, bleached wood pulp, etc. The isolation process is based on acid hydrolysis, which removes the amorphous region from the source material and leaving a highly crystalline domain that remains unaltered by acid treatment, resembles whisker or road like structure (Figure 4) [57]. Sulphuric acid and hydrochloric acid mainly used for the isolation of cellulose nanocrystals from the source material. The dimensions of cellulose nanocrystals are varied with the extraction technique and nature of the source material. Cellulose nanocrystals have the dimension in the range of 3-30 nm width and length in the range of $100 \mathrm{~nm}$ to $1 \mu \mathrm{m}$ [58-60]. During the isolation of cellulose nanocrystals by sulphuric acid hydrolysis, sulfate half ester groups will be introduced on the cellulose chain, which boosts intermolecular repulsive force, causing better dispersion of cellulose nanocrystals in the polar solvent. Cellulose nanocrystals show remarkable properties, including high surface area, excellent stability, fascinating mechanical (high modulus as well as higher specific strength), and also extraordinary optical properties. Cellulose nanocrystal has been utilized as a promising material in drug delivery, barrier films, antimicrobial film, electronic device, hybrid composite, etc. [16, 21, 61].

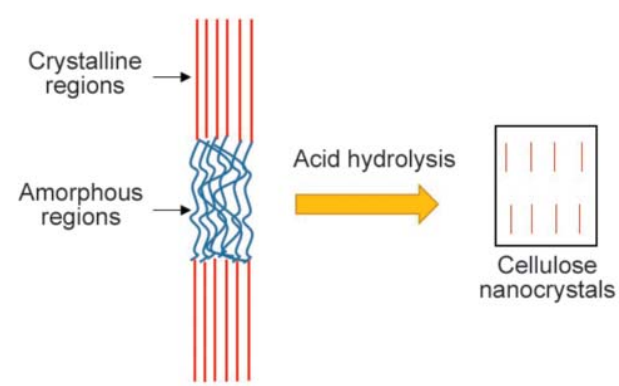

Figure 4. Schematic illustration for the extraction of cellulose nanocrystals.

\subsection{Bacterial cellulose}

Bacterial cellulose is another group of nanocellulose different from needle shape $\mathrm{CNCs}$ and fiber-like CNFs, produced by various microorganisms and bacterial species (e.g., Acetobacter xylinum, Pseudomonas). It is a rising nanomaterial with unique properties has been employed for many industrial applications such as food items, textile, cosmetic as well as the excellent capability for healthcare applications. Bacterial nanocellulose possessed higher crystallinity as compared to other groups of nanocellulose with greater flexibility, better hydrophilicity, as well as medicine release characteristics. It also possesses a high degree of polymerization (up to 8000), the elastic modulus of $78 \mathrm{GPa}$, thermal stability (around $300^{\circ} \mathrm{C}$ ), higher moisture content $(>90 \%)$, and ability to form ultrafine web structure which makes it difficult to disperse in water. Also, bacterial nanocellulose is lightweight, non-toxic, biodegradable, and also avoids traditional chemical treatment. Several reports have been indicated the utilization of bacterial nanocellulose as a transparent film, strengthening agent, and binder in the hybrid nanocomposite. The combination of conducting polymer (e.g., polypyrrole, polyaniline), and bacterial cellulose (BC) has resulted in the formation of aerogels, transparent composite, and biodegradable interconnected structure. Müller et al. [62] reported the use of bacterial nanocellulose for the preparation of a flexible membrane for organic electronics.

\section{Production of nanocellulose}

Various techniques have been developed to extract nanocellulose from plant and agriculture residue, including coconut husk fiber, jute fibers, rice straw, and potato peel, etc. The source material and different extraction techniques resulted in different types and properties of nanocellulose. Acid hydrolysis, enzymatic hydrolysis, and mechanical process are the main extraction techniques to extract nanocellulose $[31,63]$. 


\subsection{Acid hydrolysis}

Acid hydrolysis is a widely used and more convenient extraction technique to extract nanocellulose in the form of cellulose nanocrystals from natural fiber. Natural fiber exhibits ordered (cellulose) and disordered region (hemicellulose, and lignin). Cellulose nanocrystals are produced by removing the disordered region of the fiber, as well as by breaking the local crystalline contacts between nanofibrils, through acid hydrolysis at high concentration followed by high power mechanical or ultrasonic treatments. The dimension and crystallinity of cellulose nanocrystals mainly depend on the condition of acid hydrolysis; these conditions include temperature, time, and concentration of acidic reagent. Moreover, source and extraction conditions also affect the dimension and crystallinity of cellulose nanocrystals. The major drawback of this process is acidic wastewater generation due to the washing of nanocellulose with distilled water followed by centrifugation until $\mathrm{pH}$ becomes neutral [19, 39, 64]. Maiti et al. [65] reported the extraction of nanocellulose by acid hydrolysis with $47 \%$ sulfuric acid from three different types of biomass. After completion of the reaction, nanocellulose was washed with deionized water and centrifugation, followed by adding $0.5 \mathrm{~N} \mathrm{NaOH}$ for neutralizing the suspension. Sulphuric acid is the most preferred acid for acid hydrolysis because it is useful to obtain single and well-defined cellulose nanocrystals, and it also formed charged stable crystallites that can be easily isolated from an acidic solution. If $\mathrm{HCl}$ is used instead of $\mathrm{H}_{2} \mathrm{SO}_{4}$ for acid hydrolysis, the uncharged nanocellulose will be formed, and it is difficult to separate from the acidic solution [66].

\subsection{Tempo oxidation}

In recent years, TEMPO mediated oxidation has been very popular at lab scale synthesis of nanocellulose. The reaction oxidized the hydroxyl group of cellulose to carboxylate. The reaction uses 2,2,6,6-Tetramethylpiperidine-1-oxyl radical (TEMPO) as a catalyst with a primary oxidant as $\mathrm{NaClO}$ or $\mathrm{NaClO}_{2}$ in the presence of $\mathrm{NaBr}$ at alkali conditions, and the reaction can be favorable at room temperature, and it will take 1 or 2 hours to complete. The oxidized cellulose nanofiber is approximately 3-4 nm width and lengths of several micrometers with a carboxyl acid surface. The obtained cellulose nanofibers with a high aspect ratio can be used as a gas barrier film for packaging, transparent, and flexible display for electronic devices [52, 67].

\subsection{Enzymatic hydrolysis}

Acid hydrolysis and enzymatic hydrolysis are very common hydrolysis method to extract nanocellulose. In the case of acid hydrolysis, several researchers have used various acids of different concentrations such as hydrochloric acid, sulfuric acid, nitric acid, and hydrobromic acid to remove the amorphous phase of cellulose to extract nanocellulose. But the acid hydrolysis process has several consequences, such as yield many chemical wastes, and lack of specificity in their action [66]. On the other hand, in enzymatic hydrolysis, they do not require chemical reagent, peculiar solvents, and are energy effective; their optimum operating conditions are feasible and cost-effective. In this biological treatment process, an enzyme such as xylananse, laccase used for digestion or modifying cellulose fiber in mild conditions; however, this process is very time-consuming. To tackle this problem, enzymatic hydrolysis combined with various pretreatment methods to isolate nanocellulose [63, 68]. Moniruzzaman et al. [69] reported the separation of cellulose fibrils from wood chips by pretreatment with ionic liquid followed by enzymatic hydrolysis with laccase. The obtained nanocellulose possessed high thermal, and higher crystallinity compared to native wood fibers.

\subsection{Mechanical process}

The mainly used mechanical process to obtained nanocellulose is ultrasonication, high-pressure homogenization, and ball milling. In the ultrasonication process, hydrodynamic forces of the ultrasound used for the defibrillation of cellulose fibrils. In this process, liquid molecule absorb ultrasonic energy, and mechanical oscillating power is produced, resulting in the expansion, formation, and implosion of microscopic gas bubbles [70]. Tang et al. [71] isolate nanocellulose of size $10-100 \mathrm{~nm}$ by the ultrasonication for $5 \mathrm{~h}$ at $70^{\circ} \mathrm{C}$ from wood pulp filter paper with a yield of $85.38 \%$. In the high-pressure homogenization process, cellulose slurry passes into a vessel with high velocity and high pressure to isolate nanocellulose by the action of shear force and impact force in the fluid. It is generally used for large scale production of nanocellulose [66, 72]. However, high energy consumption is the major drawback of this method. Li et al. [73] extract nanocellulose with a 
diameter of 10-20 $\mathrm{nm}$ from sugarcane bagasse by high-pressure homogenization. The obtained nanocellulose has low crystallinity and low thermal stability than the original cellulose because the intermolecular and intramolecular hydrogen bonding of cellulose was broken during the high-pressure homogenization process.

Nowadays, ball milling is a widely used mechanical process for the preparation of nanocellulose because of its simple operation, and its applicability to all classes of materials. Ball milling grinds the material into powder form and isolates nanocellulose, by inducing heavy cyclic deformation in the material. It is a top-down approach to form micro to the nanoscale, and also modify the nanofiller morphology, which enhances the compatibility between filler and polymer matrix. However, the decrystallization of materials and the high energy consumption is one of the major problems associated with ball milling [74, 75]. Zhang et al. [76] prepared cellulose nanofiber with an average diameter of $100 \mathrm{~nm}$ by ball milling from softwood pulp.

\section{Surface modification of nanocellulose}

The desire to produce high-value end products from natural resources is continuously growing, in this context, in recent decades' researchers shows great interest in the nanocellulose owing to its incomparable properties such as abundance, renewability, remarkable mechanical and physical properties. However, the hydrophilic nature of the nanocellulose restricts its dispersion in the hydrophobic matrix and thus affect the physical and mechanical properties of the developed composite film [77, 78]. Consequently, many research groups work to investigate the possibilities for the surface modification of the nanocellulose either by chemical, physical and biological approaches. Nanocellulose has a large amount of reactive hydroxyl group on its surface make it feasible to modify the surface properties by various chemical modifications such as esterification, etherification, silylation, tempo mediated oxidation, polymer grafting, click reaction, amidation, and sulfonation, etc. $[79,80]$. The resulted nanocellulose after modification shows enhancement in properties for better compatibility between nanocellulose and hydrophobic host polymer. Physical treatment can also have employed on plant fiber to change the structural and surface properties without any chemical treatment and thereby affect the mechanical bonding with the matrix. The physical method involves electric discharge (corona, cold plasma), electric current, irradiation, ultrasonic, surface fibrillation, etc. to improve chemical changes, surface energy, structure, and structural properties of the fiber. The functionalized nanocellulose is mainly employed for wastewater treatment, biosensors as well as bioimaging, catalysis, and biomedical application, etc. [81].

\section{Characterization of nanocellulose}

The characterization of nanocellulose involves a vast field of analytical techniques to analyze the morphology of nanocellulose, to examine the surface of modified nanocellulose, and to figure out various features of nanocellulose such as optical characteristics, mechanical characteristics, liquid crystallinity, etc. Morphology and dimension of nanocellulose are varied with regards to the source and extraction techniques. Scanning electron microscopy, transmission electron microscopy, and atomic force microscopy are the analytical techniques employed to analyze the morphology and size of nanocellulose. Nuclear magnetic resonance and X-ray scattering are employed to analyze the crystallinity of nanocellulose. Moreover, thermogravimetric analysis (TGA/DTG) has been used to analyze the thermal stability of nanocellulose. Both SEM and TEM can be used to evaluate the morphology and size of nanocellulose as well as the aggregation of nanocellulose and the degree of dispersion. Generally, TEM is a most valuable electron microscopy technique for the characterization of nanocellulose due to high spatial resolution as compared with SEM. Due to the high-resolution power of TEM, the transmitted electrons in TEM reveal the individual crystal, which is not possible to observe with SEM. Hence, with TEM size and morphology of nanocellulose can be studied [82]. It is reported that the TEM analysis shows that the Cellulose nanofiber has a web-like structure while cellulose nanocrystals have rod-like nanocrystals. Cellulose nanofibers have a diameter in the range of 20-200 nm while cellulose nanocrystals have a diameter in the range of 3-20 $\mathrm{nm}[67,71]$. The size of nanofiber also depends on the source of natural fiber, although the size of nanocrystals does not depend on the source material. There is a small agglomeration of fibers is observed indicated the presence of intermolecular hydrogen bonding and hydrophilic interaction between nanocellulose. Besides the source of natural fiber, chemical and mechanical 
treatment also influence the size of nanocellulose fiber [54]. AFM can also serve as the most effective method to determine particle size and size distribution of nanocellulose like TEM. Particle size measured by both techniques is somewhat different. X-ray diffraction analysis is generally used to determine the crystalline structure of natural fiber before and after chemical treatment. It is widely known that cellulose is partially crystalline or amorphous in molecular structure. It shows that cellulose chains are strongly held by hydrogen bonding in the crystalline region, whereas weaker hydrogen bonding is formed in the amorphous region of cellulose. In general, native cellulose has cellulose I phase, but after chemical treatment like mercerization or bleaching process most stable form of cellulose is formed, i.e., cellulose II $[26,83]$. The crystallinity of chemical or mechanical treated fiber is more than the raw fiber due to the removal of the non-crystalline part (Hemicellulose and lignin) during the isolation process. In general, three diffraction peaks observed at $2 \theta=16$, 22 , and $35^{\circ}$, which are assigned to native cellulose I. After chemical or mechanical treatment hydroxyl group of amorphous region of cellulose get modified resulting change in crystallinity. In nanocellulose, a sharp diffraction peak appears at an angle of $2 \theta=$ $22.7^{\circ}[83,84]$. Nanocellulose having high crystallinity is useful to be used as nanofillers or additives in polymer composite $[15,85,86]$. The crystallinity of nanocellulose also varied by choice of source material and extraction technique. The crystallinity of cellulose nanofibers obtained from flax, rutabagas, and wood is 59,64 , and $54 \%$, respectively. However, the crystallinity of cellulose nanocrystals obtained from sisal, rice husk, flax, cotton, corn stover has 85.9, $76,84.9,94,80.6 \%$, respectively $[39,87]$. Generally, cellulose nanocrystals obtained from $\mathrm{HCl}$ possess higher crystallinity values compared to those made from $\mathrm{H}_{2} \mathrm{SO}_{4}$. However, an increase in the time of hydrolysis, crystallinity of nanocrystal found to be increased due to the removal of amorphous regions $[58,60]$.

Solid-state NMR is the most effective method for analyzing the crystallinity and atomic structure of nanocellulose. ${ }^{13} \mathrm{C} \mathrm{CP}-\mathrm{MAS}$ NMR is the most commonly used NMR technique to determine the phase structure of crystalline or semi-crystalline material. However, the crystallinity indices obtained by NMR spectroscopy are comparable but lower than calculated from XRD experiments [88].
Raman spectroscopy used to analyze the interfacial tension and stress-transfer between the nanocellulose and matrix material from the rate of shift of a particular Raman band due to strain or stress. Raman spectroscopy allows a non-contact approach, with spatial resolution, to evaluate the interface between nanocellulose and the matrix. Furthermore, using Raman spectroscopy, it is possible to quantify a 'work of adhesion' between the nanocellulose and the matrix $[89,90]$.

Fourier transform infrared spectroscopy (FTIR) frequently used to characterize the surface modification of nanocellulose and molecular group involves in boding between nanocellulose and matrix. Surface modification of nanocellulose involves oxidation, esterification, carbamation, and amidation reactions used to impart covalently bonded functional groups. The carboxylation of nanocellulose through TEMPOmediated oxidation is a widespread functionalization pathway to functionalize surface hydroxyl group that can be easily investigated by FTIR from the appearance of a peak at $1730 \mathrm{~cm}^{-1}$ corresponds to carbonyl band, whose intensity can be used to estimate the degree of oxidation [51].

The thermal study of cellulose fiber is essential because it is to be used as additives or nanofillers in polymer composite. The thermal behavior of cellulose fiber depends on the source and its chemical composition. Thermal degradation of natural fiber begins with an early decomposition of hemicellulose, followed by pyrolysis of lignin and depolymerization of cellulose. Higher the extractive content and smaller crystalline size increase its thermal degradation and reduce the thermal stability of natural fiber. Literature reveals that nanocellulose has high thermal stability than its respective natural fiber $[19,54]$. The thermal stability will increase due to the removal of hemicellulose and lignin content in nanocellulose after various chemical and mechanical treatments. Thus obtained nanocellulose is a promising material for thermoplastic composites [39, 91, 92]. With the incorporation of nanocellulose in the form of filler or reinforcement in the polymer matrix, the developed nanocomposite film possessed enhanced rigidity, barrier features, durability, and also flame retardancy compared to the pristine polymer film. The incorporation of a small quantity of nanocellulose in the polymer matrix is sufficient to enhance the properties of polymer composite because of the huge surface area of nanocellulose [55]. In comparison to other 
nanomaterials such as carbon nanotubes, the strength of nanocellulose is less, but as per the cost perspective, it is very cheaper than carbon nanotubes that make it more appealing for many applications. Moreover, the nanocellulose containing biocomposite film shows a higher rate of degradation compared to pristine film because nanocellulose can degrade at a faster rate at the temperature of $20-30^{\circ} \mathrm{C}$ as a result of hydrophilicity of the nanocellulose [26].

\section{Toxicology}

The toxicity of nanocellulose mainly depends on its physio-chemical properties such as surface chemistry, degree of aggregation, including particle charge, which determines particle size and shape. These properties strongly depend on the source material, a methodology to prepare nanocellulose, and post-processing. In particular, aerosolization, lyophilization, sonication, or sterilization needs to be carefully operated in the final samples. The sample contamination with toxic chemicals is another factor that might affect the toxicity study. Very limited studies have been found in the literature regarding the toxicity of nanocellulose. The effect of nanocellulose on oral and dermal toxicity has been studied by various research groups, and they found that there is no adverse effect of nanocellulose upon ingestion and contact with the skin. Besides, proinflammatory reaction and cytotoxicity (intracellular poisonous consequence) are considerably less than those for crocidolite asbestos fiber and also multiwalled carbon nanotubes. Finally, it found that the nanocellulose obtained from natural sources does not pose a greater risk to the environment and human health compared to other toxic nanomaterials [93-96].

\section{Applications of nanocellulose}

Being light weighted, non-toxicity, low thermal expansion, improved mechanical properties, gas impermeability, electrically conducting, environmentfriendly resources, and highly resistive, nanocellulose opens a great scope in the textile industry. Nanocellulose also exhibit antimicrobial property which enhances its wide area of application such as wallpaper for hospitals; impregnated textiles; food packaging materials and water filter, etc. Also, nanocellulose has the properties of UV blocking and fire retardance, etc. Nanocellulose has been used either in the polymer matrix as additives or coated on the surface of natural or synthetic fiber to improve the properties of textile material for both professional and general public uses. They improve possibilities such as durability, self-cleaning, water, and dirt repellant features. Nanocellulose also improved the physical and thermal properties of the fabric. Nanocellulose treatment on fabric enhanced the color strength of fabric dye and also improved absorbency, which also enhances the fastest cleaning of fabric [97].

Nanocellulose has potential application in biomedical science due to its unique property such as cheap in production cost, sustainability, biocompatibility, accessibility, high surface area to volume ratio, modified surface chemistry, high strength as well as the absence of toxicity. Nanocrystals and nanocellulose fiber obtained from plant resources and bacterial cellulose obtained from bacteria have a different approach in biomedical applications $[98,99]$. The biomedical application of nanocellulose is presented in Figure 5. In plant resources, cellulose is bind with hemicellulose and lignin. Here lignin protects from biological attack, and hemicellulose acts as a binder in cellulose and lignin. So for the extraction of nanocellulose, chemical or mechanical treatments are required [100]. During chemical treatment, residual amounts of chemicals left with cellulose have shown drastic effects in the body. While bacterial cellulose obtained from bacteria have dimensions of $2-3 \mathrm{~nm}$ thick and 70-80 nm long and not contain hemicellulose and lignin content. So there are not any requirements of chemical treatment and can be utilized in biomedical applications [46, 101]. However, some reports suggested that nanocellulose obtained from natural fiber (Plant resources) is better than bacterial cellulose due to inconsistent morphology. Cellulose nanocrystals obtained by the process of acid hydrolysis have been incorporated in the hydrogel to improve its mechanical property and be used in biomedical applications for drug delivery. Nanocellulose with $\mathrm{ZnO}$ and other antimicrobial agents (Silver nanoparticles, Lysozyme) shows antibacterial activity, wound healing, and tissue regeneration [102]. Nanocellulose, in combination with silk fibroin (SF) has great potential to generate a bone-grafting scaffold [56, 103]. Nanocellulose membrane shows a great affinity for cell attachment as well as proliferation due to its excessive porosity, 3D network as well as lower cytotoxicity. Besides, the membrane made up of nanocellulose possessed high water holding capacity, conformability, super flexibility, rendering it an appropriate material for wound-dressing 


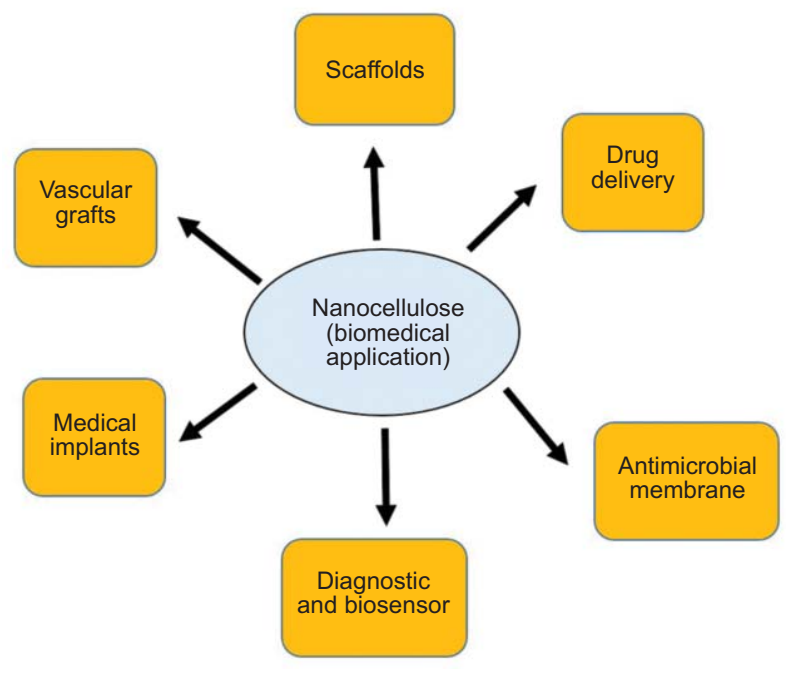

Figure 5. Biomedical applications of nanocellulose.

[31, 104]. Hasan et al. [105] reported the nanocellulose, chitosan, and PVP based nanocomposite film for wound healing drug delivery application.

The effluents of industries or natural resources contain heavy metal ions that are toxic pollutants in water. It directly affects human beings or our natural resources, so removal of pollutants is necessary. Recent advancements in nanotechnology suggested that many of the toxic pollutants in water might be removed using nanomaterials. Nanocellulose obtained from natural fibers possessed high surface area, hydrophilicity, non-toxicity, nano-size, and bio-adsorption ability, etc. Nanocellulose can be a suitable material used to remove organic pollutants (e.g., dyes, oils, pesticides, and heavy metal ions, etc.) from contaminated water (Figure 6) $[84,106]$. Liu et al. [106] reported that the cellulose nanocrystals have a higher adsorption capacity for $\mathrm{Ag}(\mathrm{I})$. Adsorption capacity depends on $\mathrm{pH}$; neutral $\mathrm{pH}$ shows high adsorption capacity. Similarly, cellulose nanofiber obtained using the method of TEMPO oxidation used to remove $\mathrm{Pb}(\mathrm{II}), \mathrm{La}(\mathrm{III})$, and $\mathrm{Ag}(\mathrm{I})$ ions from aqueous solution. Nanocellulose based membrane is also be used for water purification and a combination of another nanoparticle to improves pore structure, mechanical stability, and adsorption capacity [107, 108]. Also, nanocellulose can be modified to increase its affinity for different elements. The cationic nanocellulose shows higher adsorption capacity towards negatively charged water ions, such as fluorides, phosphates, nitrates, and sulfates. With the carboxylation of nanocellulose, it is highly reactive towards cationic pollutants such as $\mathrm{Ca}^{2+}, \mathrm{Na}^{+}, \mathrm{K}^{+}$, etc. and removes it from wastewater. Furthermore, Cellulose nanofibers

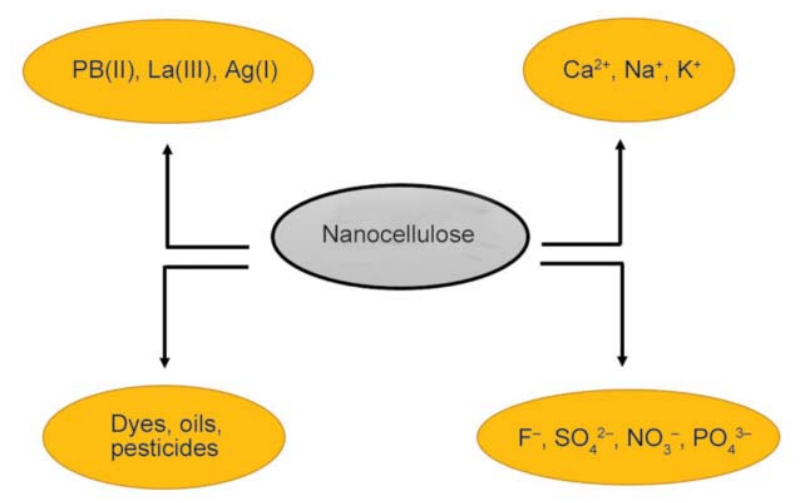

Figure 6. Nanocellulose based material for water purification.

show higher adsorption capacity towards multivalent ions $\left(\mathrm{SO}_{4}{ }^{2-}, \mathrm{PO}_{4}{ }^{3-}\right)$ than monovalent ions $\left(\mathrm{NO}^{3-}, \mathrm{F}^{-}\right)$ [109].

Nanocellulose based composite films owing to its enhanced flexibility and conductivity can be a potential material to be used in the field of electronic industry. Polyaniline nanocellulose composite film is widely used in the electronic fields such as conductive adhesives, flexible electrode, paper-based sensors, and electronic device fabrication [110 112]. Razaq et al. [113] reported the fabrication of electrodes prepared from the composite of carbon filament, nanocellulose, and polypyrrole for the efficient use of paper-based energy storage devices with high cell capacitance, high charge, and discharge capability, and cycling performance. $\mathrm{pH}$-responsive fluorescent dye grafted on the surface of cellulose nanocrystals could be successfully utilized for $\mathrm{pH}$ sensing [112, 113]. Liu et al. [49] reported that to determine toxicity in liquid samples, bacterial cellulose (BC) can also be grafted with bioluminescent bacteria that do not show luminescence in the presence of any toxic material such as pesticides, herbicides, flame retardant, etc. Esmaeili et al. [114] reported the fabrication of glucose sensors by adsorption of GOx (glucose oxidase) enzyme onto polypyrrole/cellulose nanocrystals membrane. Nanocellulose based nanopaper has high transparency, thermal stability, functionality, printability, biodegradability facilitates simple alternative of conventionally used paper, plastic, or glass substrate and can be used in electronic devices such as electrodes, sensors, actuators, electrochromic device, etc. Nanocellulose based composites are also used in different techniques such as calorimetric, nanoplasmonics, surface-enhanced Raman scattering, and electrical analysis $[115,116]$. 
The consumption of plastic in the packaging industry is increasing with an increase in consumer demand. But the plastic used in the packaging industry is nonbiodegradable, which affects the environment and human health. Because the burning of plastic enhanced greenhouse effects and also contributed to growing landfills. To provide a better quality of food to consumer, researchers have investigated the development of environment-friendly packaging material that preserves the food and provides a positive impact on consumer health. The use of bio-based material that is biodegradable, non-toxic, renewable, and abundant in nature can be a better choice for packaging material instead of synthetic non-biodegradable polymers (Figure 7) [117, 118]. The most common bio-polymer used for packaging are cellulose, chitosan, starch, collagen, etc. Some synthetic polymer has also been proposed for food packaging application i.e., Polylactic acid (PLA), Polycaprolactone (PCL), Polyvinylpyrrolidone (PVP), Polyvinylalcohol (PVA), Polyglycolic acid (PGA), etc. [119, 120]. Cellulose nanofiber-based packaging materials have been used in a wide variety of food categories such as dry food products, beverages, fresh food, and frozen or liquid foods, etc. The primary goal of using cellulose nanofiber-based packaging material is to protect and preserve the food, improve food quality, safety, and reduce food waste.

Nanocellulose extracted from plant sources used as additives or nanofillers to enhance the properties of bio-polymer or synthetic polymer (thermal, mechanical, and barrier property). Nanocellulose consists of basically two forms, one is cellulose nanocrystals obtained using acid hydrolysis, and another one is cellulose nanofiber obtained using mechanical treatments [121]. Hydroxyl group present on the surface of cellulose gives a chance for agglomeration and hinders the proper dispersion, so chemical modification is required to improve dispensability and compatibility with solvent or matrix used to prepare polymer nanocomposite. Esterification, silylation, carboxylation, polymer grafting are some common chemical treatment used to modify the property of nanocellulose and after modification nanocellulose used as nanofiller or additives in the polymer matrix to enhance the thermal, mechanical and barrier property of polymer nanocomposite [122]. El Miri et al. [123] reported that the bio nanocomposites film made up of nanocellulose had enhanced water and oxygen barrier properties, high elastic modulus, and tensile strength. Solvent casting and melt blending methods have been commonly used to prepare polymer nanocomposite. Composite materials are mainly comprised of the polymer matrix and filler material as the reinforcement to enhance the property of developed composite. The glass fiber, aramid, or carbon are usually employed as the filler into the polymeric matrix to boost the thermal as well as the mechanical properties of composite material. But the artificial filler based composite materials have some problems associated with it, such as its limited combustibility, disposability, and toxicity $[6,7]$. Thus, the use of natural filler such as starch, cellulose fiber, or chitin as reinforcement in polymer matrix will be the alternative of artificial filler due to its lesser cost, lesser density, biodegradability, excellent thermal, and mechanical properties. Both cellulose nanocrystals and cellulose nanofibers reinforcement in polymer matrix emerging as a new class of material with extremely interesting properties such as stiffness combined with low weight, biodegradability, and renewability $[47,80]$. During the last two decades', intensive research have been carried out in this area by utilizing nanocellulose in the form of nanocrystal and cellulose nanofibers in different proportion. On the other side, it has some disadvantages like high moisture absorption, poor wettability, incompatible with most of the polymer matrix. It also starts degradation at $220^{\circ} \mathrm{C}$ and restricts

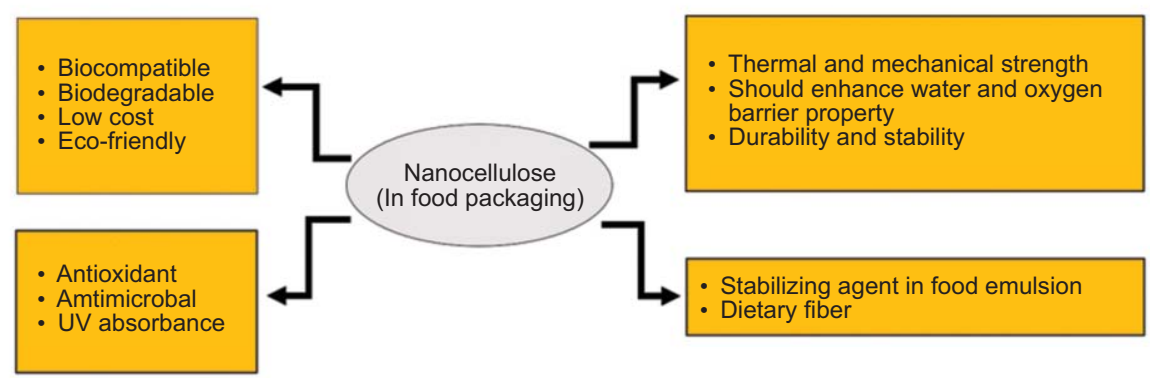

Figure 7. Nanocellulose based material for food packaging. 


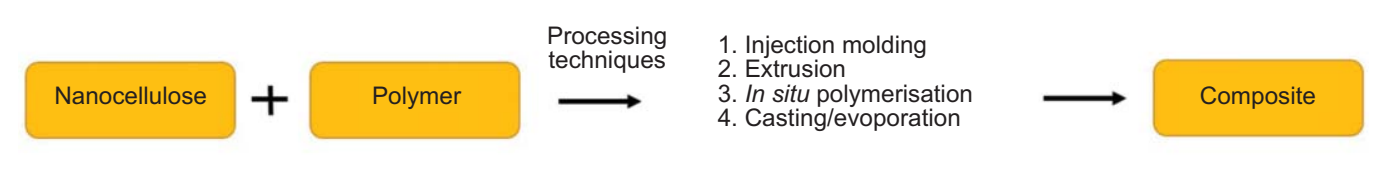

Figure 8. Processing techniques to prepare nanocomposite film.

the use of matrix, which can be used with nanocellulose. Many thermoplastics and thermoset polymer have been used as the matrix for nanocellulose, few of these are polylactic acid (PLA) [124], Polyvinyl alcohol (PVA) [75], polyurethane, hydroxypropyl cellulose (HPC) [125], Chitosan [126], polyacrylamide [127], etc. PVP and PVA are synthetic polymers, has high tensile strength, flexibility, inexpensive, nontoxic, biocompatible, and having good physical or chemical property.

Many research groups are working on the incorporation of nanocellulose into it with different proportions to observe thermal, mechanical, and biodegradable properties of PVA/Nanocellulose composite [75]. Many research groups also working on thermoset polymers like epoxy, formaldehyde, and polyester, etc. to prepare nanocomposite with the addition of nanocellulose. The nanocomposite of epoxy-nanocellulose has a potential application due to its high mechanical properties. Different techniques have been used to prepare polymer nanocomposite films such as solvent casting, melt blending, grinding, injection molding, melt extrusion, etc. (Figure 8) [20]. Besides, the above application nanocellulose can also use as the thickener in the cosmetics, filler of special textile, $\mathrm{CO}_{2}$ adsorbent, and oil recovery.

\section{Conclusions}

This present review article enhances the knowledge about the fundamentals, properties, characterization, and practical application of nanocellulose. It provides significant information about the work done so far in the preparation of nanocellulose, surface modification as well as utilization of it in numerous applications. The utilization of non-biodegradable and non-renewable materials in various applications has raised concerns over environmental pollution. In recent years' cellulose nanomaterials are considered as a viable alternative of conventionally used nanomaterials because of low fabrication cost, safer to handle, completely renewable with exceptional chemical and physical properties. Chemical, as well as mechanical method, has been employed on natural fiber to obtain nanocellulose of various kinds. However, the mechanical method to prepare nanocellulose shows some advantages over chemical methods due to its eco-friendly and chemical-free, but it has some drawbacks like high energy consumption, and prepared nanocellulose may not be compatible with many applications. However, the hydrophilicity of nanocellulose limits its use in various applications, so various modification techniques employed on nanocellulose due to the presence of several hydrox$y l$ groups present on its surface. Therefore, nanocellulose can be incorporate into a wide range of polymer matrix as reinforcement or filler to obtain the desired properties. With appropriate extraction techniques and with various surface modification nanocellulose developed as the most promising bio-based material for use in applications ranging artificial skin and cartilage, wound healing and vessel substitutes, scaffolds in tissue engineering, and biodegradable food packaging. But still, some research should be required on size, orientation, porosity needs to be controlled to be used in biomedical applications. Nanocellulose also shows various applications in paper and board industry, oil and gas, filtration, aerogels, 3D printing, rheology modifiers, and flexible electronics. The incorporation of a minimal amount of nanocellulose in a polymer matrix could enhance the physical and mechanical features of the material compared to the pristine polymer matrix alone. Furthermore, various organic and inorganic materials were employed to composite along with nanocellulose to fabricate high-performance polymer composite. Undoubtedly, there are certain challenge has come across in the path of commercializing it such as large production cost and also requires quite a long time, to tackle this problem, further fundamental research is required. In closing, nanocellulose based materials will have a bright future in the nano era with the advancement of science and technology. This review will help researchers in the selection, development of the various forms of nanocellulose, and nanocellulose based composite materials for advancement in a wide range of applications. 


\section{Acknowledgements}

The authors acknowledge the GGSIP University, New Delhi for providing financial assistance. We would also like to thank the lab staff of BTL-311/315 (USBAS) for their invaluable support and guidance to make this research successful.

\section{References}

[1] Abba H. A., Nur I. Z., Salit S. M.: Review of agro waste plastic composites production. Journal of Minerals and Materials Characterization and Engineering, 1, 271279 (2013).

https://doi.org/10.4236/jmmce.2013.15041

[2] Ashori A., Nourbakhsh A.: Bio-based composites from waste agricultural residues. Waste Management, 30, 680-684 (2010).

https://doi.org/10.1016/j.wasman.2009.08.003

[3] Mochane M. J., Mokhena T. C., Mokhothu T. H., Mtibe A., Sadiku E. R., Ray S. S., Ibrahim I. D., Daramola O. O.: Recent progress on natural fiber hybrid composites for advanced applications: A review. Express Polymer Letters, 13, 159-198 (2019).

https://doi.org/10.3144/expresspolymlett.2019.15

[4] Franco T. S., Amezcua R. M. J., Rodrìguez A. V., Enriquez S. G., Urquíza M. R., Mijares E. M., de Muniz G. B.: Carboxymethyl and nanofibrillated cellulose as additives on the preparation of chitosan biocomposites: Their influence over films characteristics. Journal of Polymers and the Environment, 28, 676-688 (2020). https://doi.org/10.1007/s10924-019-01639-0

[5] Manimaran P., Saravanan S. P., Sanjay M. R., Jawaid M., Siengchin S., Fiore V.: New lignocellulosic aristida adscensionis fibers as novel reinforcement for composite materials: Extraction, characterization and weibull distribution analysis. Journal of Polymers and the Environment, 28, 803-811 (2019). https://doi.org/10.1007/s10924-019-01640-7

[6] Singh D., Dubey P., Pradhan M., Singh M. R.: Ceramic nanocarriers: Versatile nanosystem for protein and peptide delivery. Expert Opinion on Drug Delivery, 10, 241-259 (2013).

https://doi.org/10.1517/17425247.2012.745848

[7] Singh D., Singh S., Sahu J., Srivastava S., Singh M. R.: Ceramic nanoparticles: Recompense, cellular uptake and toxicity concerns. Artificial Cells, Nanomedicine, and Biotechnology, 44, 401-409 (2016). https://doi.org/10.3109/21691401.2014.955106

[8] Shvedova A. A., Kagan V. E., Fadeel B.: Close encounters of the small kind: Adverse effects of manmade materials interfacing with the nano-cosmos of biological systems. Annual Review of Pharmacology and Toxicology, 50, 63-88 (2010).

https://doi.org/10.1146/annurev.pharmtox.010909.105819

[9] Kumar R., Kumari S., Surah S. S., Rai B., Kumar R., Sirohi S., Kumar G.: A simple approach for the isolation of cellulose nanofibers from banana fibers. Materials Research Express, 6, 105601/1-105601/12 (2019). https://doi.org/10.1088/2053-1591/ab3511
[10] Supranto S., Yuliansyah A. T., Yunanto D. E.: Sugarcane bagasse conversion to high refined cellulose using nitric acid, sodium hydroxide and hydrogen peroxide as the delignificating agents. Journal of Engineering Science and Technology, 10, 35-46 (2015). https://doi.org/10.13140/2.1.5063.2641

[11] Johar N., Ahmad I., Dufresne A.: Extraction, preparation and characterization of cellulose fibres and nanocrystals from rice husk. Industrial Crops and Products, 37, 93-99 (2012).

https://doi.org/10.1016/j.indcrop.2011.12.016

[12] Abdul Khalil H. P. S., Tye Y. Y., Saurabh C. K., Leh C. P., Lai T. K., Chong E. W. N., Nurul Fazita M. R., Hafiidz J. M., Banerjee A., Syakir M. I.: Biodegradable polymer films from seaweed polysaccharides: A review on cellulose as a reinforcement material. Express Polymer Letters, 11, 244-265 (2017).

https://doi.org/10.3144/expresspolymlett.2017.26

[13] Clemons C.: Nanocellulose in spun continuous fibers: A review and future outlook. Journal of Renewable Materials, 4, 327-339 (2016). https://doi.org/10.7569/JRM.2016.634112

[14] Lin N., Huang J., Dufresne A.: Preparation, properties and applications of polysaccharidenanocrystals in advanced functional nanomaterials: A review. Nanoscale, 4, 3274-3294 (2012).

https://doi.org/10.1039/c2nr30260h

[15] Cao X., Ding B., Yu J., Al-Deyab S. S.: Cellulose nanowhiskers extracted from TEMPO-oxidized jute fibers. Carbohydrate Polymers, 90, 1075-1080 (2012). https://doi.org/10.1016/j.carbpol.2012.06.046

[16] Jonoobi M., Oladi R., Davoudpour Y., Oksman K., Dufresne A., Hamzeh Y., Davoodi R.: Different preparation methods and properties of nanostructured cellulose from various natural resources and residues: A review. Cellulose, 22, 935-969 (2015). https://doi.org/10.1007/s10570-015-0551-0

[17] Jawaid M., Khalil H. P. S. A., Bakar A. A., Khanam P. N.: Chemical resistance, void content and tensile properties of oil palm/jute fibre reinforced polymer hybrid composites. Materials and Design, 32, 1014-1019 (2011). https://doi.org/10.1016/j.matdes.2010.07.033

[18] Sajna V. P., Mohanty S., Nayak S. K.: Fabrication and characterization of bionanocomposites based on poly (lactic acid), banana fiber and nanoclay. International Journal of Plastics Technology, 20, 187-201 (2016). https://doi.org/10.1007/s12588-014-9088-6

[19] Abraham E., Deepa B., Pothan L. A., Jacob M., Thomas S., Cvelbar U., Anandjiwala R.: Extraction of nanocellulose fibrils from lignocellulosic fibres: A novel approach. Carbohydrate Polymers, 86, 14681475 (2011).

https://doi.org/10.1016/j.carbpol.2011.06.034 
[20] Li Y-Y., Wang B., Ma M-G., Wang B.: Review of recent development on preparation, properties, and applications of cellulose-based functional materials. International Journal of Polymer Science, 2018, 8973643/18973643/18 (2018).

https://doi.org/10.1155/2018/8973643

[21] Xu X., Liu F., Jiang L., Zhu J. Y., Haagenson D., Wiesenborn D. P.: Cellulose nanocrystals vs. cellulose nanofibrils: A comparative study on their microstructures and effects as polymer reinforcing agents. ACS Applied Materials and Interfaces, 5, 2999-3009 (2013). https://doi.org/10.1021/am302624t

[22] Tayeb A., Amini E., Ghasemi S., Tajvidi M.: Cellulose nanomaterials - Binding properties and applications: A review. Molecules, 23, 2684/1-2684/24 (2018). https://doi.org/10.3390/molecules23102684

[23] Hoeng F., Denneulin A., Bras J.: Use of nanocellulose in printed electronics: A review. Nanoscale, 8, 1313113154 (2016). https://doi.org/10.1039/C6NR03054H

[24] Bras J., Viet D., Bruzzese C., Dufresne A.: Correlation between stiffness of sheets prepared from cellulose whiskers and nanoparticles dimensions. Carbohydrate Polymers, 84, 211-215 (2011). https://doi.org/10.1016/j.carbpol.2010.11.022

[25] Zhu H., Xiao Z., Liu D., Li Y., Weadock N. J., Fang Z., Huang J., Hu L.: Biodegradable transparent substrates for flexible organic-light-emitting diodes. Energy and Environmental Science, 6, 2105-2111 (2013). https://doi.org/10.1039/c3ee40492g

[26] Sharma A., Thakur M., Bhattacharya M., Mandal T., Goswami S.: Commercial application of cellulose nanocomposites - A review. Biotechnology Reports, 21, e00316/1-e00316/15 (2019). https://doi.org/10.1016/j.btre.2019.e00316

[27] Feng L., Xie N., Zhong J.: Carbon nanofibers and their composites: A review of synthesizing, properties and applications. Materials, 7, 3919-3945 (2014). https://doi.org/10.3390/ma7053919

[28] Kang H., Liu R., Huang Y.: Graft modification of cellulose: Methods, properties and applications. Polymer, 70, A1-A16 (2015). https://doi.org/10.1016/j.polymer.2015.05.041

[29] Ng H-M., Sin L. T., Bee S-T., Tee T-T., Rahmat A. R.: Review of nanocellulose polymer composite characteristics and challenges. Polymer-Plastics Technology and Engineering, 56, 687-731 (2017). https://doi.org/10.1080/03602559.2016.1233277

[30] Klemm D., Kramer F., Moritz S., Lindström T., Ankerfors M., Gray D., Dorris A.: Nanocelluloses: A new family of nature-based materials. Angewandte Chemie International Edition, 50, 5438-5466 (2011). https://doi.org/10.1002/anie.201001273

[31] Nair S. S., Zhu J., Deng Y., Ragauskas A. J.: High performance green barriers based on nanocellulose. Sustainable Chemical Processes, 2, 23/1-23/7 (2014). https://doi.org/10.1186/s40508-014-0023-0
[32] Luo Y., Zhang J., Li X., Liao C., Li X.: The cellulose nanofibers for optoelectronic conversion and energy storage. Journal of Nanomaterials, 2014, 654512/1654512/13 (2014). https://doi.org/10.1155/2014/654512

[33] Kim J-H., Shim B. S., Kim H. S., Lee Y-J., Min S-K., Jang D., Abas Z., Kim J.: Review of nanocellulose for sustainable future materials. International Journal of Precision Engineering and Manufacturing - Green Technology, 2, 197-213 (2015). https://doi.org/10.1007/s40684-015-0024-9

[34] Saba N., Tahir P. M., Jawaid M.: A review on potentiality of nano filler/natural fiber filled polymer hybrid composites. Polymers, 6, 2247-2273 (2014). https://doi.org/10.3390/polym6082247

[35] Chirayil C. J., Mathew L., Thomas S.: Review of recent research in Nanocellulose preparation and application from jute fibers. Reviews on Advanced Materials Science, 37, 20-28 (2014).

[36] Mat Zain N. F., Yusop S. M., Ahmad I.: Preparation and characterization of cellulose and nanocellulose from pomelo (Citrus grandis) albedo. Journal of Nutrition and Food Sciences, 5, 1000334/1-1000334/4 (2014). https://doi.org/10.4172/2155-9600.1000334

[37] Akil H. M., Omar M. F., Mazuki A. A. M., Safiee S., Ishak Z. A. M., Abu Bakar A.: Kenaf fiber reinforced composites: A review. Materials and Design, 32, 41074121 (2011). https://doi.org/10.1016/j.matdes.2011.04.008

[38] Saxena M., Pappu A., Sharma A., Haque R., Wankhede S.: Composite materials from natural resources: Recent trends and future potentials. Advances in Composite Materials - Analysis of Natural and Man-Made Materials, (2011).

https://doi.org/10.5772/18264

[39] Morán J. I., Alvarez V. A., Cyras V. P., Vázquez A.: Extraction of cellulose and preparation of nanocellulose from sisal fibers. Cellulose, 15, 149-159 (2008). https://doi.org/10.1007/s10570-007-9145-9

[40] Gonçalves A. P. B., de Miranda C. S., Guimarães D. H., de Oliveira J. C., Cruz A. M. F., da Silva F. L. B. M., Luporini S., José N. M.: Physicochemical, mechanical and morphologic characterization of purple banana fibers. Materials Research, 18, 205-209 (2015). https://doi.org/10.1590/1516-1439.366414

[41] Luo X., Wang X.: Preparation and characterization of nanocellulose fibers from $\mathrm{NaOH} /$ urea pretreatment of oil palm fibers. BioResources, 12, 5826-5837 (2017). https://doi.org/10.15376/biores.12.3.5826-5837

[42] Milani M. D. Y., Samarawickrama D. S., Dharmasiri G. P. C. A., Kottegoda I. R. M.: Study the structure, morphology, and thermal behavior of banana fiber and its charcoal derivative from selected banana varieties. Journal of Natural Fibers, 13, 332-342 (2016). https://doi.org/10.1080/15440478.2015.1029195 
[43] Kulasinski K., Keten S., Churakov S. V., Derome D., Carmeliet J.: A comparative molecular dynamics study of crystalline, paracrystalline and amorphous states of cellulose. Cellulose, 21, 1103-1116 (2014). https://doi.org/10.1007/s10570-014-0213-7

[44] Khazraji A. C., Robert S.: Self-assembly and intermolecular forces when cellulose and water interact using molecular modeling. Journal of Nanomaterials, 2013, 745979/1-745979/12 (2013).

https://doi.org/10.1155/2013/745979

[45] Samzadeh-Kermani A., Esfandiary N.: Synthesis and characterization of new biodegradable chitosan/polyvinyl alcohol/cellulose nanocomposite. Advances in Nanoparticles, 5, 18-26 (2016).

https://doi.org/10.4236/anp.2016.51003

[46] Ostadhossein F., Mahmoudi N., Morales-Cid G., Tamjid E., Navas-Martos F., Soriano-Cuadrado B., Paniza J., Simchi A.: Development of chitosan/bacterial cellulose composite films containing nanodiamonds as a potential flexible platform for wound dressing. Materials, 8, 6401-6418 (2015). https://doi.org/10.3390/ma8095309

[47] Habibi Y., Lucia L. A., Rojas O. J.: Cel cellulose nanocrystals: Chemistry, self-assembly, and applications. Chemical Reviews, 110, 3479-3500 (2010). https://doi.org/10.1021/cr900339w

[48] Cao X., Dong H., Li C. M.: New nanocomposite materials reinforced with flax cellulose nanocrystals in waterborne polyurethane. Biomacromolecules, 8 , 899 904 (2007). https://doi.org/10.1021/bm0610368

[49] Liu J., Korpinen R., Mikkonen K. S., Willför S., Xu C.: Nanofibrillated cellulose originated from birch sawdust after sequential extractions: A promising polymeric material from waste to films. Cellulose, 21, 2587-2598 (2014).

https://doi.org/10.1007/s10570-014-0321-4

[50] Srithep Y., Turng L-S., Sabo R., Clemons C.: Nanofibrillated cellulose (NFC) reinforced polyvinyl alcohol (PVOH) nanocomposites: Properties, solubility of carbon dioxide, and foaming. Cellulose, 19, 1209-1223 (2012). https://doi.org/10.1007/s10570-012-9726-0

[51] Ferrer A., Quintana E., Filpponen I., Solala I., Vidal T., Rodríguez A., Laine J., Rojas O. J.: Effect of residual lignin and heteropolysaccharides in nanofibrillar cellulose and nanopaper from wood fibers. Cellulose, 19, 2179-2193 (2012).

https://doi.org/10.1007/s10570-012-9788-Z

[52] Chen Y., Geng B., Ru J., Tong C., Liu H.: Comparative characteristics of TEMPO-oxidized cellulose nanofibers and resulting nanopapers from bamboo, softwood, and hardwood pulps. Cellulose, 24, 4831-4844 (2017). https://doi.org/10.1007/s10570-017-1478-4

[53] Lin J., Yu L., Tian F., Zhao N., Li X., Bian F., Wang J.: Cellulose nanofibrils aerogels generated from jute fibers. Carbohydrate Polymers, 109, 35-43 (2014). https://doi.org/10.1016/j.carbpol.2014.03.045
[54] Rambabu N., Panthapulakkal S., Sain M., Dalai A. K.: Production of nanocellulose fibers from pinecone biomass: Evaluation and optimization of chemical and mechanical treatment conditions on mechanical properties of nanocellulose films. Industrial Crops and Products, 83, 746-754 (2016).

https://doi.org/10.1016/j.indcrop.2015.11.083

[55] Kumar R., Kumari S., Rai B., Das R., Kumar G.: Effect of nano-cellulosic fiber on mechanical and barrier properties of polylactic acid (PLA) green nanocomposite film. Materials Research Express, 6, 125108/1125108/12 (2019). https://doi.org/10.1088/2053-1591/ab5755

[56] Halib N., Perrone F., Cemazar M., Dapas B., Farra R., Abrami M., Chiarappa G., Forte G., Zanconati F., Pozzato G., Murena L., Fiotti N., Lapasin R., Cansolino L., Grassi G., Grassi M.: Potential applications of nanocellulose-containing materials in the biomedical field. Materials, 10, 977/1-977/31 (2017). https://doi.org/10.3390/ma10080977

[57] Kumar A., Negi Y. S., Choudhary V., Bhardwaj N. K.: Characterization of cellulose nanocrystals produced by acid-hydrolysis from sugarcane bagasse as agrowaste. Journal of Materials Physics and Chemistry, 2, $1-8$ (2014).

https://doi.org/10.12691/jmpc-2-1-1

[58] Huntley C. J., Crews K. D., Abdalla M. A., Russell A. E., Curry M. L.: Influence of strong acid hydrolysis processing on the thermal stability and crystallinity of cellulose isolated from wheat straw. International Journal of Chemical Engineering, 2015, 1-11 (2015). https://doi.org/10.1155/2015/658163

[59] Gopi S., Amalraj A., Jude S., Benson K. T., Balakrishan P., Haponiuk J. T., Thomas S.: Isolation and characterization of stable nanofiber from turmeric spent using chemical treatment by acid hydrolysis and its potential as antimicrobial and antioxidant activities. Journal of Macromolecular Science Part A: Pure and Applied Chemistry, 56, 327-340 (2019). https://doi.org/10.1080/10601325.2019.1578613

[60] Han G., Huan S., Han J., Zhang Z., Wu Q.: Effect of acid hydrolysis conditions on the properties of cellulose nanoparticle-reinforced polymethylmethacrylate composites. Materials, 7, 16-29 (2014). https://doi.org/10.3390/ma7010016

[61] Roman M.: Toxicity of cellulose nanocrystals: A review. Industrial Biotechnology, 11, 25-33 (2015). https://doi.org/10.1089/ind.2014.0024

[62] Müller D., Cercená R., Gutiérrez Aguayo A. J., Porto L. M., Rambo C. R., Barra G. M. O.: Flexible PEDOTnanocellulose composites produced by in situ oxidative polymerization for passive components in frequency filters. Journal of Materials Science: Materials in Electronics, 27, 8062-8067 (2016). https://doi.org/10.1007/s10854-016-4804-y 
[63] Mukwaya V., Yu W., Asad R. A., Yagoub H.: An environmentally friendly method for the isolation of cellulose nanofibrils from banana rachis fibers. Textile Research Journal, 87, 81-90 (2017). https://doi.org/10.1177/0040517515622155

[64] Jahan M. S., Saeed A., He Z., Ni Y.: Jute as raw material for the preparation of microcrystalline cellulose. Cellulose, 18, 451-459 (2011). https://doi.org/10.1007/s10570-010-9481-z

[65] Maiti S., Jayaramudu J., Das K., Reddy S. M., Sadiku R., Ray S. S., Liu D.: Preparation and characterization of nanocellulose with new shape from different precursor. Carbohydrate Polymers, 98, 562-567 (2013). https://doi.org/10.1016/j.carbpol.2013.06.029

[66] Phanthong P., Reubroycharoen P., Hao X., Xu G., Abudula A.: Nanocellulose: Extraction and application. Carbon Resources Conversion, 1, 32-43 (2018). https://doi.org/10.1016/j.crcon.2018.05.004

[67] Serra A., González I., Oliver-Ortega H., Tarrès Q., Delgado-Aguilar M., Mutjé P.: Reducing the amount of catalyst in TEMPO-oxidized cellulose nanofibers: Effect on properties and cost. Polymers, 9, 557/1557/14 (2017). https://doi.org/10.3390/polym9110557

[68] Dammak A., Moreau C., Beury N., Schwikal K., Winter H. T., Bonnin E., Saake B., Cathala B.: Elaboration of multilayered thin films based on cellulose nanocrystals and cationic xylans: Application to xylanase activity detection. Holzforschung, 67, 579-586 (2013). https://doi.org/10.1515/hf-2012-0176

[69] Moniruzzaman M., Ono T.: Separation and characterization of cellulose fibers from cypress wood treated with ionic liquid prior to laccase treatment. Bioresource Technology, 127, 132-137 (2013). https://doi.org/10.1016/j.biortech.2012.09.113

[70] Eichhorn S. J., Dufresne A., Aranguren M., Marcovich N. E., Capadona J. R., Rowan S. J., Weder C., Thielemans W., Roman M., Renneckar S., Gindl W., Veigel S., Keckes J., Yano H., Abe K., Nogi M., Nakagaito A. N., Mangalam A., Simonsen J., Benight A. S., Bismarck A., Berglund L. A., Peijs T.: Review: Current international research into cellulose nanofibres and nanocomposites. Journal of Materials Science, 45, $1-33(2010)$. https://doi.org/10.1007/s10853-009-3874-0

[71] Tang Z., Li W., Lin X., Xiao H., Miao Q., Huang L., Chen L., Wu H.: TEMPO-oxidized cellulose with high degree of oxidation. Polymers, 9, 421-431 (2017). https://doi.org/10.3390/polym9090421

[72] Kargarzadeh H., Huang J., Lin N., Ahmad I., Mariano M., Dufresne A., Thomas S., Gałęski A.: Recent developments in nanocellulose-based biodegradable polymers, thermoplastic polymers, and porous nanocomposites. Progress in Polymer Science, 87, 197-227 (2018).

https://doi.org/10.1016/j.progpolymsci.2018.07.008
[73] Li J., Wei X., Wang Q., Chen J., Chang G., Kong L., $\mathrm{Su}$ J., Liu Y.: Homogeneous isolation of nanocellulose from sugarcane bagasse by high pressure homogenization. Carbohydrate Polymers, 90, 1609-1613 (2012). https://doi.org/10.1016/j.carbpol.2012.07.038

[74] Abbasi R., Baheti V.: Preparation of nanocellulose from jute fiber waste. Journal of Textile Engineering and Fashion Technology, 4, 101-104 (2018). https://doi.org/10.15406/jteft.2018.04.00126

[75] Baheti V., Militky J.: Reinforcement of wet milled jute nano/micro particles in polyvinyl alcohol films. Fibers and Polymers, 14, 133-137 (2013). https://doi.org/10.1007/s12221-013-0133-4

[76] Zhang L., Tsuzuki T., Wang X.: Preparation of cellulose nanofiber from softwood pulp by ball milling. Cellulose, 22, 1729-1741 (2015). https://doi.org/10.1007/s10570-015-0582-6

[77] Spoljaric S., Salminen A., Luong N. D., Seppälä J.: Ductile nanocellulose-based films with high stretchability and tear resistance. European Polymer Journal, 69, 328-340 (2015). https://doi.org/10.1016/j.eurpolymj.2015.06.019

[78] Cheng Z. L., Xu Q. H., Gao Y.: Research progress in nanocellulose modification. Advanced Materials Research, 627, 859-863 (2012).

https://doi.org/10.4028/www.scientific.net/AMR.627.859

[79] Ferreira F. V., Pinheiro I. F., de Souza S. F., Mei L. H. I., Lona L. M. F.: Polymer composites reinforced with natural fibers and nanocellulose in the automotive industry: A short review. Journal of Composites Science, 3, 51/1-51/17 (2019).

https://doi.org/10.3390/jcs3020051

[80] Kargarzadeh H., Mariano M., Huang J., Lin N., Ahmad I., Dufresne A., Thomas S.: Recent developments on nanocellulose reinforced polymer nanocomposites: A review. Polymer, 132, 368-393 (2017).

https://doi.org/10.1016/j.polymer.2017.09.043

[81] Ljungberg N., Bonini C., Bortolussi F., Boisson C., Heux L., Cavaillé J. Y.: New nanocomposite materials reinforced with cellulose whiskers in atactic polypropylene: Effect of surface and dispersion characteristics. Biomacromolecules, 6, 2732-2739 (2005). https://doi.org/10.1021/bm050222v

[82] Krishnamachari P., Hashaikeh R., Tiner M.: Modified cellulose morphologies and its composites; SEM and TEM analysis. Micron, 42, 751-761 (2011). https://doi.org/10.1016/j.micron.2011.05.001

[83] Lani N. S., Ngadi N., Johari A., Jusoh M.: Isolation, characterization, and application of nanocellulose from oil palm empty fruit bunch fiber as nanocomposites. Journal of Nanomaterials, 2014, 702538/1-702538/9 (2014). https://doi.org/10.1155/2014/702538

[84] Nascimento P., Marim R., Carvalho G., Mali S.: Nanocellulose produced from rice hulls and its effect on the properties of biodegradable starch films. Materials Research, 19, 167-174 (2016). https://doi.org/10.1590/1980-5373-MR-2015-0423 
[85] Chakraborty S., Kundu S. P., Roy A., Adhikari B., Majumder S. B.: Polymer modified jute fibre as reinforcing agent controlling the physical and mechanical characteristics of cement mortar. Construction and Building Materials, 49, 214-222 (2013).

https://doi.org/10.1016/j.conbuildmat.2013.08.025

[86] Brinchi L., Cotana F., Fortunati E., Kenny J. M.: Production of nanocrystalline cellulose from lignocellulosic biomass: Technology and applications. Carbohydrate Polymers, 94, 154-169 (2013). https://doi.org/10.1016/j.carbpol.2013.01.033

[87] Dufresne A.: Nanocellulose: A new ageless bionanomaterial. Materials Today, 16, 220-227 (2013). https://doi.org/10.1016/j.mattod.2013.06.004

[88] Kim S. H., Lee C. M., Kafle K.: Characterization of crystalline cellulose in biomass: Basic principles, applications, and limitations of XRD, NMR, IR, Raman, and SFG. Korean Journal of Chemical Engineering, 30, 2127-2141 (2013). https://doi.org/10.1007/s11814-013-0162-0

[89] Lewandowska A. E., Eichhorn S. J.: Quantification of the degree of mixing of cellulose nanocrystals in thermoplastics using Raman spectroscopy. Journal of Raman Spectroscopy, 47, 1337-1342 (2016). https://doi.org/10.1002/jrs.4966

[90] Rusli R., Eichhorn S. J.: Interfacial energy dissipation in a cellulose nanowhisker composite. Nanotechnology, 22, 325706/1-325706/8 (2011). https://doi.org/10.1088/0957-4484/22/32/325706

[91] Kinloch A. J., Taylor A. C., Techapaitoon M., Teo W. S., Sprenger S.: Tough, natural-fibre composites based upon epoxy matrices. Journal of Materials Science, $\mathbf{5 0}$, 6947-6960 (2015). https://doi.org/10.1007/s10853-015-9246-z

[92] Dilamian M., Noroozi B.: A combined homogenization-high intensity ultrasonication process for individualizaion of cellulose micro-nanofibers from rice straw. Cellulose, 26, 5831-5849 (2019). https://doi.org/10.1007/s10570-019-02469-y

[93] Zoppe J. O., Ruottinen V., Ruotsalainen J., Rönkkö S., Johansson L-S., Hinkkanen A., Järvinen K., Seppälä J.: Synthesis of cellulose nanocrystals carrying tyrosine sulfate mimetic ligands and inhibition of alphavirus infection. Biomacromolecules, 15, 1534-1542 (2014). https://doi.org/10.1021/bm500229d

[94] Ni H., Zeng S., Wu J., Cheng X., Luo T., Wang W., Zeng W., Chen Y.: Cellulose nanowhiskers: Preparation, characterization and cytotoxicity evaluation. Bio-Medical Materials and Engineering, 22, 121-127 (2012). https://doi.org/10.3233/BME-2012-0697

[95] Clift M. J. D., Foster E. J., Vanhecke D., Studer D., Wick P., Gehr P., Rothen-Rutishauser B., Weder C.: Investigating the interaction of cellulose nanofibers derived from cotton with a sophisticated 3D human lung cell coculture. Biomacromolecules, 12, 36663673 (2011).

https://doi.org/10.1021/bm200865j
[96] Fröhlich E., Roblegg E.: Models for oral uptake of nanoparticles in consumer products. Toxicology, 291, 10-17 (2012). https://doi.org/10.1016/j.tox.2011.11.004

[97] Salah S. M.: Application of nano-cellulose in textile. Journal of Textile Science and Engineering, 3, 1000142/1 (2013).

https://doi.org/10.4172/2165-8064.1000142

[98] Rajwade J. M., Paknikar K. M., Kumbhar J. V: Applications of bacterial cellulose and its composites in biomedicine. Applied Microbiology and Biotechnology, 99, 2491-2511 (2015) https://doi.org/10.1007/s00253-015-6426-3

[99] Abitbol T., Rivkin A., Cao Y., Nevo Y., Abraham E., Ben-Shalom T., Lapidot S., Shoseyov O.: Nanocellulose, a tiny fiber with huge applications. Current Opinion in Biotechnology, 39, 76-88 (2016). https://doi.org/10.1016/j.copbio.2016.01.002

[100] Kumar R., Rai B., Kumar G.: A simple approach for the synthesis of cellulose nanofiber reinforced chitosan/PVP bio nanocomposite film for packaging. Journal of Polymers and the Environment, 27, 2963-2973 (2019). https://doi.org/10.1007/s10924-019-01588-8

[101] Fu L. N., Wang W., Yu L. J., Zhang S. M., Yang G.: Fabrication of novel cellulose/chitosan artificial skin composite. Materials Science Forum, 610, 1034-1038 (2009).

https://doi.org/10.4028/www.scientific.net/MSF.610-613.1034

[102] Jorfi M., Foster E. J.: Recent advances in nanocellulose for biomedical applications. Journal of Applied Polymer Science, 132, 41719/1-41719/19 (2015). https://doi.org/10.1002/app.41719

[103] Park S., Baker J. O., Himmel M. E., Parilla P. A., Johnson D. K.: Cellulose crystallinity index: Measurement techniques and their impact on interpreting cellulase performance. Biotechnology for Biofuels, 3, 10/1-10/10 (2010). https://doi.org/10.1186/1754-6834-3-10

[104] Hu Y., Tang L., Lu Q., Wang S., Chen X., Huang B.: Preparation of cellulose nanocrystals and carboxylated cellulose nanocrystals from borer powder of bamboo. Cellulose, 21, 1611-1618 (2014). https://doi.org/10.1007/s10570-014-0236-0

[105] Hasan A., Waibhaw G., Tiwari S., Dharmalingam K., Shukla I., Pandey L. M.: Fabrication and characterization of chitosan, polyvinylpyrrolidone, and cellulose nanowhiskers nanocomposite films for wound healing drug delivery application. Journal of Biomedical Materials Research: Part A, 105, 2391-2404 (2017). https://doi.org/10.1002/jbm.a.36097

[106] Liu L., Gao Z. Y., Su X. P., Chen X., Jiang L., Yao J. M.: Adsorption removal of dyes from single and binary solutions using a cellulose-based bioadsorbent. ACS Sustainable Chemistry and Engineering, 3, 432-442 (2015). https://doi.org/10.1021/sc500848m 
[107] Zhong L-X., Peng X-W., Yang D., Sun R-C.: Adsorption of heavy metals by a porous bioadsorbent from lignocellulosic biomass reconstructed in an ionic liquid. Journal of Agricultural and Food Chemistry, 60, 5621-5628 (2012).

https://doi.org/10.1021/jf301182x

[108] Elbariji S., Pétrissans A., Elamine M., Ouzaouit K., Kabli H., Albourine A., Gerardin P.: Removal of $\mathrm{Cu}^{2+}$ from aqueous solutions by adsorption on chemically modified cellulosic supports. Particulate Science and Technology, 29, 320-332 (2011). https://doi.org/10.1080/02726351.2010.499561

[109] Voisin H., Bergström L., Liu P., Mathew A.: Nanocellulose-based materials for water purification. Nanomaterials, 7, 57/1-57/19 (2017). https://doi.org/10.3390/nano7030057

[110] Zhang D., Zhang Q., Gao X., Piao G.: A nanocellulose polypyrrole composite based on tunicate cellulose. International Journal of Polymer Science, 2013, 175609/1175609/6 (2013). https://doi.org/10.1155/2013/175609

[111] Wang Z., Tammela P., Zhang P., Huo J., Ericson F., Strømme M., Nyholm L.: Freestanding nanocellulosecomposite fibre reinforced 3D polypyrrole electrodes for energy storage applications. Nanoscale, 6, 13068 13075 (2014). https://doi.org/10.1039/C4NR04642K

[112] Tammela P., Wang Z., Frykstrand S., Zhang P., Sintorn I-M., Nyholm L., Strømme M.: Asymmetric supercapacitors based on carbon nanofibre and polypyrrole/ nanocellulose composite electrodes. RSC Advances, 5, 16405-16413 (2015). https://doi.org/10.1039/C4RA15894F

[113] Razaq A., Nyholm L., Sjödin M., Strømme M., Mihranyan A.: Paper-based energy-storage devices comprising carbon fiber-reinforced polypyrrolecladophora nanocellulose composite electrodes. Advanced Energy Materials, 2, 445-454 (2012). https://doi.org/10.1002/aenm.201100713

[114] Esmaeili C., Abdi M., Mathew A., Jonoobi M., Oksman K., Rezayi M.: Synergy effect of nanocrystalline cellulose for the biosensing detection of glucose. Sensors, 15, 24681-24697 (2015). https://doi.org/10.3390/s151024681

[115] Shi Z., Phillips G. O., Yang G.: Nanocellulose electroconductive composites. Nanoscale, 5, 3194-3201 (2013). https://doi.org/10.1039/c3nr00408b

[116] Palanisamy S., Cheemalapati S., Chen S-M.: Amperometric glucose biosensor based on glucose oxidase dispersed in multiwalled carbon nanotubes/graphene oxide hybrid biocomposite. Material Science and Engineering: C, 34, 207-213 (2014). https://doi.org/10.1016/j.msec.2013.09.011

[117] Trifol J., Plackett D., Sillard C., Szabo P., Bras J., Daugaard A. E.: Hybrid poly(lactic acid)/nanocellulose/ nanoclay composites with synergistically enhanced barrier properties and improved thermomechanical resistance. Polymer International, 65, 988-995 (2016). https://doi.org/10.1002/pi.5154
[118] Lavoine N., Desloges I., Dufresne A., Bras J.: Microfibrillated cellulose - Its barrier properties and applications in cellulosic materials: A review. Carbohydrate Polymers, 90, 735-764 (2012).

https://doi.org/10.1016/j.carbpol.2012.05.026

[119] Shankar S., Rhim J-W.: Polymer nanocomposites for food packaging applications. in 'Functional and physical properties of polymer nanocomposites' (eds.: Dasari A., Njuguna J.) Wiley, Chichester, 29-55 (2016). https://doi.org/10.1002/9781118542316.ch3

[120] Ronald Aseer J., Sankaranarayanasamy K., Jayabalan P., Natarajan R., Priya Dasan K.: Morphological, physical, and thermal properties of chemically treated banana fiber. Journal of Natural Fibers, 10, 365-380 (2013) https://doi.org/10.1080/15440478.2013.824848

[121] Arrieta M. P., Fortunati E., Dominici F., López J., Kenny J. M.: Bionanocomposite films based on plasticized PLA-PHB/cellulose nanocrystal blends. Carbohydrate Polymers, 121, 265-275 (2015). https://doi.org/10.1016/j.carbpol.2014.12.056

[122] Galotto M., Ulloa P., Escobar R., Guarda A., Gavara R., Miltz J.: Effect of high-pressure food processing on the mass transfer properties of selected packaging materials. Packaging and Technology and Science, 23, 253-266 (2010). https://doi.org/10.1002/pts.893

[123] El Miri N., Abdelouahdi K., Barakat A., Zahouily M., Fihri A., Solhy A., El Achaby M.: Bio-nanocomposite films reinforced with cellulose nanocrystals: Rheology of film-forming solutions, transparency, water vapor barrier and tensile properties of films. Carbohydrate Polymers, 129, 156-167 (2015). https://doi.org/10.1016/j.carbpol.2015.04.051

[124] Robles E., Urruzola I., Labidi J., Serrano L.: Surfacemodified nano-cellulose as reinforcement in poly(lactic acid) to conform new composites. Industrial Crops and Products, 71, 44-53 (2015). https://doi.org/10.1016/j.indcrop.2015.03.075

[125] de Carvalho Benini K. C. C., Cioffi M. O. H., Voorwald H. J. C.: PHBV/cellulose nanofibrils composites obtained by solution casting and electrospinning process. Matéria (Rio de Janeiro), 22, e11837/1-e11837/9 (2017).

https://doi.org/10.1590/s1517-707620170002.0170

[126] Kumar R., Rahman H., Ranwa S., Kumar A., Kumar G.: Development of cost effective metal oxide semiconductor based gas sensor over flexible chitosan/PVP blended polymeric substrate. Carbohydrate Polymers, 239, 116213/1-116213/7 (2020). https://doi.org/10.1016/j.carbpol.2020.116213

[127] Li K., Wang Y., Huang M., Yan H., Yang H., Xiao S., Li A.: Preparation of chitosan-graft-polyacrylamide magnetic composite microspheres for enhanced selective removal of mercury ions from water. Journal of Colloid and Interface Science, 455, 261-270 (2015). https://doi.org/10.1016/j.jcis.2015.05.043 